\title{
PNAIC no Estado do Rio de Janeiro: jogos matemáticos na prática de professores do Ciclo de Alfabetização
}

\author{
Edite Resende Vieira \\ Colégio Pedro II \\ Projeto Fundão-IM-UFRJ \\ edite.resende@gmail.com
}

\section{Elizabeth Ogliari Marques}

Projeto Fundão-IM-UFRJ

bethogliari@gmail.com

\begin{abstract}
Resumo
O uso de jogos nas práticas escolares, como elemento mediador dos conteúdos a serem abordados, contribui para que a criança potencialize sua possibilidade de aprender e de construir novos conhecimentos. Nesta comunicação, apresentamos reflexões acerca da utilização de jogos como alternativa didático-pedagógica para os professores do Ciclo de Alfabetização em um programa de formação continuada implementado pelo governo federal. Tal programa, pautado em atividades problematizadoras, possibilitou ao professor alfabetizador perceber o jogo como um recurso de ensino favorável à (re)construção de conceitos matemáticos e à troca de pontos de vista. Foi possível constatar também que a interação propiciada pelo jogo e o saber dos professores serviram como base para momentos de reflexão e de (res)significação das práticas pedagógicas no ensino de Matemática. Para finalizar, ficou evidente a importância da intencionalidade docente e a intervenção pedagógica na prática de jogos para promover a construção de conceitos matemáticos.
\end{abstract}

Palavras-chave: Jogos. Formação de Professores. Ciclo de Alfabetização. PNAIC.

\section{PNAIC in the State of Rio de Janeiro: math games in the practices of Literacy Cycle teacher}

\begin{abstract}
The use of games in teaching practices, as a mediating element of the contents covered, contributes for the child to leverage their learning process and to build knowledge. In this communication, we present some reflections about the use of games as a didactic-pedagogical alternative for Literacy Cycle teachers in a continuous education program implemented by the federal government. Based on problematizing activities, such a program enabled the literacy teacher to understand games as a resource favorable to the (re)construction of math concepts and to the exchange of viewpoints. It was also possible to assert that the interaction provided by the game and the teachers' knowledge served as a foundation for some moments of reflection and the (re)signification of the pedagogical practice when teaching Mathematics. To conclude, the importance of the teacher's intentionality and the pedagogical intervention in the practice of games were essential to foster the construction of math concepts.
\end{abstract}

Keywords: Games. Teacher Training. Literacy Cycle. PNAIC. 


\section{Introdução}

O Ciclo de Alfabetização é parte integrante dos anos iniciais do Ensino Fundamental. A maioria dos professores que atua nesse estágio do ensino não possui o saber disciplinar nem o saber pedagógico da Matemática e, consequentemente, seu saber experiencial fica aquém do necessário ao exercício de suas funções. Consideramos, como Shulman (1986), Ball (1988), Tardif (2002) e Serrazina (2012), indispensável o saber disciplinar, o saber pedagógico, o saber curricular e o saber experiencial para o pleno exercício da função de ensinar pelo professor.

Concordamos com Mandarino (2006, p. 230), ao afirmar que "nesse nível de ensino os professores não têm formação específica e muitos declaram sequer gostar de matemática [...] sem dúvida a formação inicial e continuada dos professores dos anos iniciais precisa ser repensada". Pudemos constatar esse fato quando atuamos como formadoras e/ou supervisoras em programas de formação continuada.

Os problemas referentes ao ensino de Matemática ainda são evidentes no cenário brasileiro. De acordo com os Parâmetros Curriculares Nacionais (BRASIL, 1997), tais problemas referem-se ao processo de formação do magistério, tanto em relação à formação inicial quanto à formação continuada.

Embora crianças e jovens, inseridos no mundo digital, das redes sociais e da realidade virtual, vivenciem novas formas de relação com o saber, é comum encontrarmos professores dos anos iniciais desenvolvendo, ainda, em suas aulas, práticas de Matemática que priorizam um ensino pautado em cálculos e procedimentos. Isso se justifica porque os professores, como afirmam Nacarato et al. (2009, p. 23), “[...] trazem crenças arraigadas sobre o que seja Matemática, seu ensino e sua aprendizagem. Tais crenças, na maioria das vezes, acabam por contribuir para a constituição da prática profissional”.

Procurando melhorar os processos de ensino e aprendizagem no Ciclo de Alfabetização, o governo federal tem promovido ações de formação continuada para professores que atuam nesse segmento de ensino. Desde 2013, o Ministério da Educação (MEC), visando à alfabetização de todos os alunos ao final do terceiro ano do Ensino Fundamental, até os 8 anos de idade, vem implementando o Programa Nacional pela Alfabetização na Idade Certa (PNAIC). Tal programa, pautado em atividades problematizadoras e interdisciplinares, proporcionou aos professores oportunidades de vivenciar diferentes metodologias no ensino de Matemática, utilizando diversos recursos pedagógicos, como por exemplo, o jogo, levando-os a refletir sobre as potencialidades desse recurso nos processos de ensinar e de aprender. A opção pelo jogo se justifica, uma vez que nem sempre os professores do Ciclo de Alfabetização têm a percepção das contribuições que os jogos podem oferecer no contexto educacional. 
Diante do exposto e a partir de nossa experiência como supervisoras do PNAIC, decidimos investigar, no referido programa de formação continuada, as contribuições que o jogo proporciona ao professor do Ciclo de Alfabetização na (re)construção de conceitos matemáticos e na reflexão sobre/para a prática pedagógica.

Nessa comunicação, o foco será a formação do PNAIC em 2014, quando foram trabalhados treze cadernos voltados para a alfabetização matemática. A partir de nossa experiência como supervisoras do PNAIC, apresentamos reflexões acerca das ações realizadas pelos professores orientadores de estudos de uma turma do Polo Campos dos Goytacazes, no Estado do Rio de Janeiro, ao vivenciarem jogos matemáticos direcionados aos alunos do Ciclo de Alfabetização.

\section{PNAIC no Estado do Rio de Janeiro}

O Pacto Nacional pela Alfabetização na Idade Certa (PNAIC) é um acordo formal assumido pelo Governo Federal, estados, municípios e entidades para firmar o compromisso de alfabetizar crianças até, no máximo, 8 anos de idade, ao final do Ciclo de Alfabetização. Em 2013, o foco do PNAIC foi a alfabetização em Língua Portuguesa. Já em 2014, o ponto principal da formação foi a alfabetização matemática em uma perspectiva interdisciplinar com a Língua Portuguesa. Preconizava-se que em 2015 o cerne seria também a interdisciplinaridade, propiciando a interlocução entre todas as disciplinas trabalhadas no Ciclo de Alfabetização.

A equipe em 2014 era formada por uma coordenadora geral, dois coordenadores adjuntos, dez supervisores, 54 professores formadores (27 de Língua Portuguesa e 27 de Matemática) e 654 orientadores de estudo e um coordenador local em cada município participante do PNAIC. Em cada Polo, o supervisor tinha sob sua orientação os formadores que, por sua vez, formavam os orientadores de estudo. Os orientadores de estudo formavam os professores alfabetizadores em seus municípios. Essa ação, em 2014, atingiu aproximadamente 14000 professores alfabetizadores.

A instituição responsável pelo PNAIC no Estado do Rio de Janeiro é a Universidade Federal do Rio de Janeiro. A coordenação geral e a coordenação de Língua Portuguesa são da Faculdade de Educação. Em 2014, a coordenação de Matemática ficou a cargo do Projeto Fundão, do Instituto de Matemática da mesma universidade, mas em 2015, tal coordenação foi extinta.

\section{Formação de Professores}

Não se pode responsabilizar apenas a formação inicial dos professores pelo caos em que se encontra a educação brasileira; entretanto, sabe-se que os professores do Ciclo de Alfabetização e, de forma 
mais geral, dos anos iniciais do Ensino Fundamental, são polivalentes, ou seja, ensinam várias disciplinas, apesar de sua formação inicial não garantir essa polivalência.

Hoje, no município do Rio de Janeiro convivem formação superior - o Curso Normal Superior e o Curso de Pedagogia - e a formação de nível médio. Para exercer a função de professor dos anos iniciais do Ensino Fundamental, no qual se inclui o Ciclo de Alfabetização, nesse município, a formação mínima exigida, segundo o Edital SMA № 92, de 26 de fevereiro de 2016, contempla essa diversidade.

Visitando o site de oito instituições, envolvendo universidades e faculdades públicas ou privadas, que oferecem o curso de Pedagogia, verificamos que os currículos são diversos e que nem todas as ementas dos cursos estavam disponibilizadas. Em visita a uma escola pública, de Ensino Médio, com formação de professores, também percebemos a insuficiência da formação matemática dos estudantes dessa modalidade. Ficou evidente que várias dessas instituições desenvolvem a formação matemática de seus alunos, futuros professores, de maneiras distintas e, nossa experiência em processos formativos com professores, e em particular com os orientadores de estudo do PNAIC, evidenciou que a formação matemática está bastante aquém da necessidade desses profissionais.

Ao longo do tempo, foram várias as ações de formação continuada de professores dos anos iniciais do Ensino Fundamental desenvolvidas pelo poder público. Nas duas mais abrangentes, o Pró-Letramento e o PNAIC, participamos como supervisoras nas discussões sobre o ensino e a aprendizagem de Matemática no Ciclo de Alfabetização. Nas ações vivenciadas pelos professores foi possível constatar o quanto é importante focar a formação do professor na prática reflexiva.

Muitos pesquisadores da formação e profissão docente defendem uma nova abordagem de formação que tem como suporte o conceito da reflexão. Donald Schön foi um dos autores que teve maior destaque ao abordar o conceito de reflexão. A reflexão, na concepção de Schön (1997), engloba duas categorias: a reflexão na ação e a reflexão sobre a ação. $\mathrm{Na}$ reflexão na ação o professor reflete sobre as ações que realiza durante as atividades, ou seja, ele reformula as suas ações no decorrer de sua intervenção profissional. Nessa perspectiva, a reflexão na e sobre a ação deve ser ressaltada como elemento essencial na formação inicial e contínua dos professores, de modo a servir como estímulo na utilização de seu practicum reflexivo às mudanças de suas práticas.

Serrazina (2012) dá destaque à reflexão sobre a prática para o desenvolvimento do conhecimento profissional docente. Em suas pesquisas, Serrazina (2012) verificou que a formação de professores deve configurar-se como um processo formativo que ofereça aos docentes diferentes atividades matemáticas dos tipos realizadas com os alunos em sala de aula. De acordo com a autora citada anteriormente, é possível que os professores se envolvam em experiências de aprendizagem, 
“[...] experimentem o conhecimento e a 'vivência pessoal' dos processos e da natureza da atividade matemática" (SERRAZINA, 2012, p. 282) e possam refletir sobre essas experiências.

Ball (1988) também entende que é fundamental oferecer aos professores dos anos iniciais oportunidades para que possam elaborar situações de aprendizagem, vivenciá-las com seus alunos na sala de aula e refletir sobre essas experiências.

À vista disso, a proposta desenvolvida pelo PNAIC, além de buscar o aprimoramento do saber disciplinar, do saber pedagógico e do saber experiencial dos orientadores de estudo, propõe uma formação que tem como suporte o conceito da reflexão. A partir de uma variedade de atividades realizadas pelos professores orientadores, procurou-se olhar com atenção para a construção do saber disciplinar matemático, do saber pedagógico, analisando como o aluno aprende determinados conceitos, discutindo suas dificuldades e as estratégias para ajudá-los a superá-las, buscando a troca de experiência entre os pares, o que sempre foi apontado como um ponto altamente positivo da proposta do PNAIC.

No nosso entendimento, uma formação continuada eficaz deve confrontar os professores com situações nas quais eles conheçam novas formas de ensinar Matemática ao mesmo tempo em que aprendem os conceitos básicos da matemática elementar. Acreditamos que dessa forma eles terão oportunidade de construir o saber pedagógico disciplinar da Matemática.

\section{Os saberes dos professores}

Comparando testes de avaliação de professores aplicados no século XIX e na década de 1980, Shulman (1986) percebeu que o saber do conteúdo era o saber valorizado no século XIX. Posteriormente o foco deixou de ser "o que ensinar" para ser "como ensinar". Na tentativa de retomar o reconhecimento do saber do professor sobre aquilo que fundamenta o conteúdo do ensino e da aprendizagem, Shulman (1986) se interessou em investigar o conhecimento que os professores têm dos conteúdos de ensino e como esses conteúdos se transformam durante o ensino. Seu interesse consistia, também, em saber como determinados conhecimentos e as estratégias de ensino interagem nas mentes dos professores. Em seus estudos, o referido autor destaca sete categorias que compõem a base de conhecimentos dos professores, indispensáveis a sua ação efetiva, e as agrupa em três: conhecimento do conteúdo, conhecimento pedagógico do conteúdo e conhecimento curricular.

Shulman (1986) considera relevante o reconhecimento, pelo professor, das estratégias com as quais os conteúdos são compreendidos e adquirem significados para os alunos. Para esse autor, o conhecimento pedagógico do conteúdo é indispensável para a atuação docente. 
Quando se fala nos saberes do professor, Serrazina (2012) corrobora as ideias de Shulman (1986). De acordo com a autora, é indispensável para o professor ter o domínio dos conhecimentos matemáticos a ensinar, como também ter conhecimento das estratégias para ensiná-los.

Pesquisando sobre os conhecimentos que os professores polivalentes têm da Matemática a ser ensinada, Ball (1988) observou a necessidade de os professores compreenderem profundamente a Matemática que ensinam. Para a autora, a compreensão da Matemática para ser ensinada envolve o conhecimento de conceitos, proposições e procedimentos matemáticos, o conhecimento da estrutura da Matemática e de relações entre temas matemáticos.

Tardif (2002) ainda apresenta a categoria dos saberes experienciais, aqueles que brotam da atividade docente e que são validados pela experiência, que são compartilhados pelos professores e que se incorporam ao saber pedagógico disciplinar. Esse foi um ponto forte do PNAIC: oportunizar a troca de experiências entre os orientadores de estudo e os formadores, entre orientadores de estudo, e entre estes e os professores que eles formavam em seus municípios.

Não queremos e nem podemos afirmar que o conhecimento do conteúdo da Matemática seja suficiente para garantir a efetividade da ação docente. No entanto, compartilhando das ideias de Ball (1988), acreditamos ser fundamental que o professor conheça o assunto a ensinar e que esse conhecimento deva ser adequadamente considerado na preparação e na certificação dos professores.

\section{Jogos matemáticos como recurso pedagógico}

Os estudos de Vygotsky (1998) dão destaque à interação social no processo de construção das funções psicológicas humanas. Segundo o referido autor, a relação com o outro, em qualquer atividade humana, contribui essencialmente para o processo de construção do ser psicológico individual. Contudo, tal atividade não se forma por si só na criança, mas por meio da comunicação prática e verbal com as pessoas ao seu redor, uma vez que o indivíduo é determinado pelas interações sociais, isto é, pela relação com o outro. Nessa perspectiva, podemos citar o jogo como uma atividade que promove a interação social, segundo a concepção de Vygotsky (1998).

A utilização de jogos nas aulas de Matemática tem sido foco de estudos de vários pesquisadores. De acordo com Silva (2005), no ensino por meio de jogos, o professor desenvolve aulas mais interessantes e o aluno se sente mais motivado a frequentar as aulas, tornando-se agente nos processos de ensino e aprendizagem. Moretti e Souza (2015) afirmam que, ao brincar ou jogar, a criança desenvolve sua oportunidade de aprender e de se apropriar de novos conhecimentos. No entender de Silveira e Barone (1998, p. 2), os jogos na sala de aula “[...] podem ser empregados em uma variedade de propósitos dentro do contexto de aprendizado. Um dos usos básicos e muito importantes é a possibilidade de construir-se a autoconfiança”. 
Compartilhando das ideias desses autores, Smole et al. (2007, p. 9) ressaltam que "[...] o jogo possibilita uma situação de prazer e aprendizagem significativa nas aulas de matemática”.

Além do comprometimento de pesquisadores no estudo das potencialidades dos jogos no ensino e na aprendizagem de Matemática, no domínio público esta iniciativa também se fez presente. Desde o final dos anos 90, alguns documentos oficiais orientam a utilização de jogos matemáticos na sala de aula como um recurso didático capaz de prover um ensino e uma aprendizagem mais dinâmicos. De acordo com os Parâmetros Curriculares Nacionais de Matemática (BRASIL, 1997), por meio de jogos, as crianças vivenciam situações repetitivas, aprendem a operar com símbolos e a pensar por analogia. Segundo o documento, “[...] é importante que os jogos façam parte da cultura escolar, cabendo ao professor analisar e avaliar a potencialidade educativa dos diferentes jogos e o aspecto curricular que se deseja desenvolver" (BRASIL, 1997. p. 36).

Outro aspecto de grande relevância refere-se à ludicidade presente nos jogos pedagógicos. Sobre isso, Moyles (2002) assegura que a estimulação, a variedade, o interesse, a concentração e a motivação são igualmente garantidos pela situação lúdica presente nos jogos.

Corroborando Moyles (2002), Fialho (2007, p.16) salienta que "a exploração do aspecto lúdico, pode se tornar uma técnica facilitadora na elaboração de conceitos, [...] tornando esse processo transparente, ao ponto que o domínio sobre os objetivos propostos na obra seja assegurado".

Embora a ludicidade se evidencie nas atividades envolvendo jogos, é importante que o professor seja um mediador da aprendizagem ao utilizar esse recurso na sala de aula, fazendo as intervenções necessárias, de modo a propiciar um ambiente no qual o aluno seja capaz de levantar e validar hipóteses, criar estratégias de solução, argumentar e se tornar um sujeito autônomo. Portanto, o jogo não deve ser escolhido aleatoriamente, sem fins pedagógicos.

De acordo com Starepravo (2009), a intencionalidade docente na prática de jogos para a construção de conceitos matemáticos deve fazer parte de um projeto de ensino do professor. As orientações expressas no caderno "Jogos na Alfabetização Matemática”, proposto pelo PNAIC, vêm corroborar tais afirmações:

[...] para que o ato de jogar na sala de aula se caracterize como uma metodologia que favoreça a aprendizagem, o papel do professor é essencial. Sem a intencionalidade pedagógica do professor, corre-se o risco de se utilizar o jogo sem explorar seus aspectos educativos, perdendo grande parte de sua potencialidade (BRASIL, 2014, p. 5).

Na utilização do jogo como recurso didático, o professor propicia condições para que o aluno desempenhe um papel ativo na construção do conhecimento, desenvolva-se nos aspectos sócio afetivo e cognitivo, vivencie o cumprimento e o estabelecimento coletivo de regras, interaja 
com os demais e tome decisões, desenvolvendo a autonomia e o pensamento lógico-matemático. Ao jogar, os alunos estão intrinsecamente motivados a pensar e a lembrar de fatos ocorridos, o que facilita a construção ou internalização de conceitos e procedimentos matemáticos. Cabe ao professor orientar a atividade, podendo seguir determinadas etapas, tais como: familiarização com o material; reconhecimento das regras; jogo para internalização das regras; jogo "para valer"; intervenção pedagógica oral e escrita como uma forma de problematizar as situações do jogo; registro do jogo para auxiliar na análise e chegar à formalização das conclusões.

Diante disso, o uso de jogos matemáticos nas práticas docentes requer um planejamento bem organizado, com metodologia cuidadosamente explicitada e objetivos definidos. Consequentemente, sua utilização pode auxiliar os alunos no processo de construção de conhecimentos e propiciar ao professor momentos de reflexão sobre sua prática, evitando o uso do jogo pelo jogo, ou seja, sem fins pedagógicos.

\section{Atividades com jogos matemáticos desenvolvidas no PNAIC}

Apresentamos nesta seção duas atividades com jogos realizadas pelos professores orientadores durante a formação. O primeiro jogo a ser apresentado é o jogo "Corrida de Peões" (Brasil, 2014).

Esse jogo é composto por um tabuleiro, dois dados comuns e seis peões, jogado por duas equipes. As equipes escolhem dois peões numerados (1 a 13) indicados no tabuleiro. Os dados são lançados por cada uma. A soma das faces sorteadas indicará o número do peão da equipe que avançará uma casa do tabuleiro. As somas obtidas são anotadas no tabuleiro para que cada peão avance na corrida. Vence a equipe que finalizar a corrida com um de seus peões. A Figura 1 representa o tabuleiro do jogo.

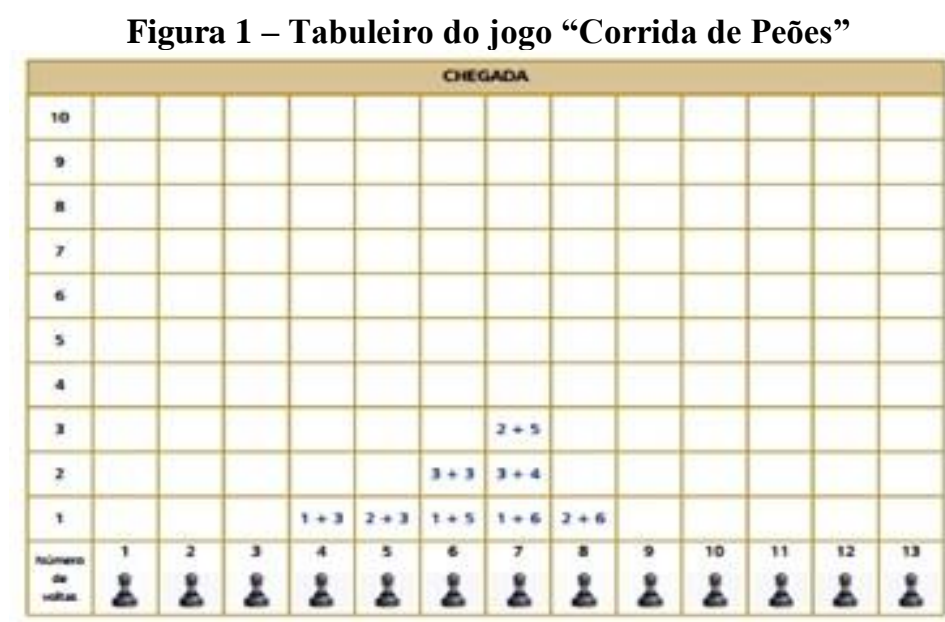

Fonte: Acervo pessoal.

A escolha por esse jogo se justifica porque possibilita o diálogo com mais de um campo da Matemática: Educação Estatística e Números e Operações. Durante as etapas do jogo, foi possível 
investigar e explorar o conceito de chance e possibilidade, e os fatos básicos da adição. Após a discussão das regras, os seguintes questionamentos, sugeridos aos alunos no caderno "Jogos na Alfabetização Matemática" (BRASIL, 2014), foram propostos aos professores orientadores, desencadeando uma discussão sobre a forma como os conteúdos matemáticos envolvidos são explorados com esse recurso:

- Se você tivesse que escolher um dos peões para ganhar a corrida, qual você escolheria? Por quê?

- Qual o peão que dará o maior número de voltas? Por quê?

- Quais os peões que ficarão para trás? Por quê?

- Quais peões não ganharão a corrida? Por quê?

- Quais peões têm mais chances de ganhar o jogo? Por quê?

Os questionamentos levantados durante a discussão propiciaram um ambiente no qual os professores se viram em um movimento contínuo de aprender a aprender. Na figura 2 apresentamos momentos do jogo com os professores orientadores.

Figura 2 - Momentos do jogo "Corrida de Peões"
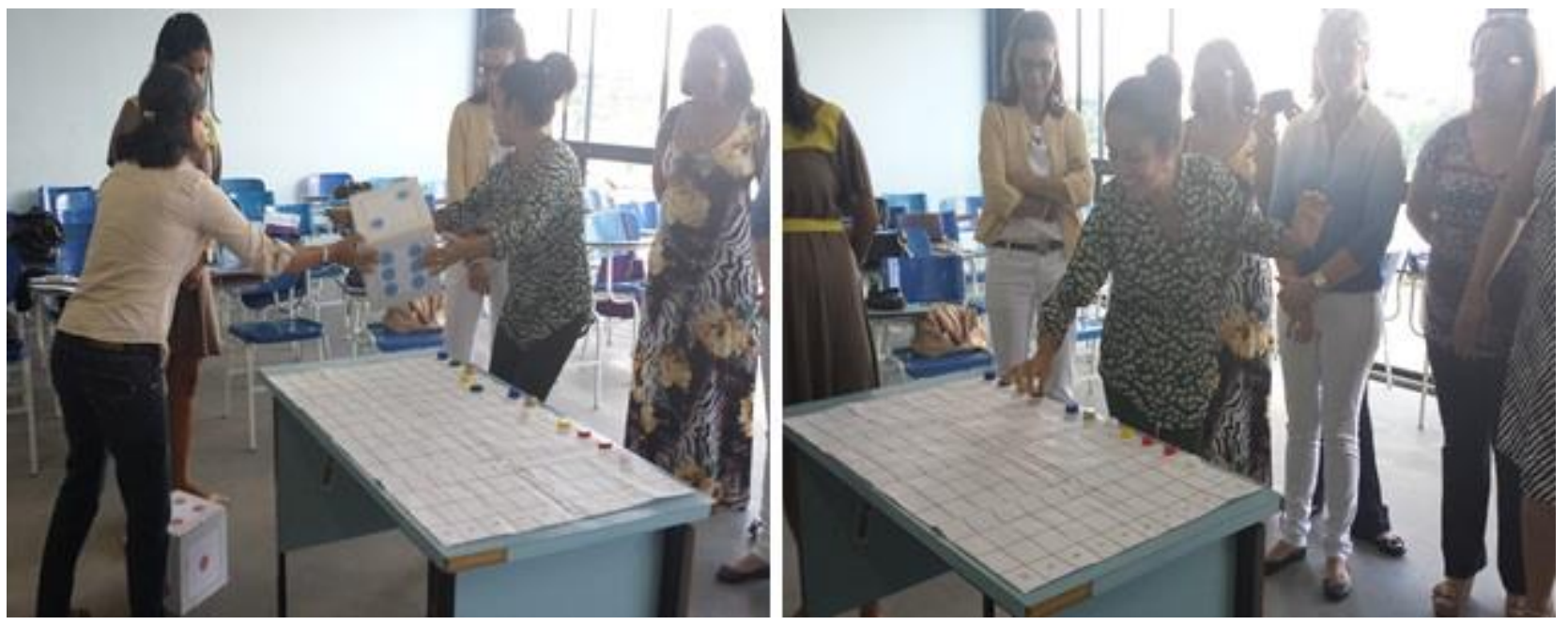

Fonte: Acervo pessoal.

Observamos durante as jogadas que os professores mobilizaram o conhecimento do conteúdo específico (SHULMAN, 1986) ao perceberem que algumas somas possuem mais chances de serem sorteadas do que outras. Tal constatação é resultado das discussões e reflexões realizadas pelos professores durante a aplicação do jogo (BALL, 1988; SCHÖN, 1997; SERRAZINA, 2012).

Outro jogo vivenciado pelos professores foi o "Jogo da Testa". Esse jogo explora o cálculo mental nas operações de adição e subtração e estimula a reversibilidade de pensamento. Um momento do jogo com os professores orientadores está representado na figura 3. 


\section{Figura 3 - Momento do "Jogo da Testa"}

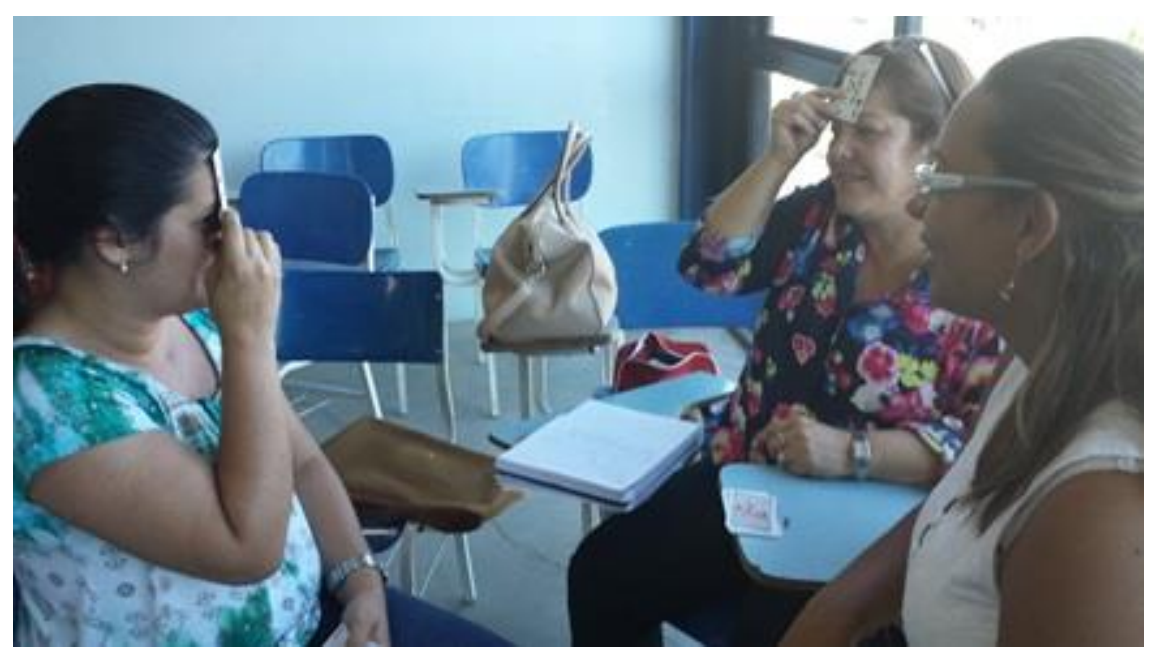

Fonte: Acervo pessoal.

Na dinâmica do jogo participam dois jogadores e um juiz. Cada jogador recebe cartas de baralho, de 1 a 9, e as arruma em um monte. A seguir, retira uma carta de seu monte e, sem olhá-la, coloca-a na testa com a face numerada voltada para o jogador adversário. Cada jogador vê somente a carta do oponente. $\mathrm{O}$ juiz olha as duas cartas e dita a soma das duas. $\mathrm{O}$ jogador que disser primeiro o número de sua carta, fica com as duas. Vence o jogo, o jogador que ficar com mais cartas, ao terminarem os montes.

Assim como no jogo "Corrida de Peões", os professores foram instigados a responder perguntas de exploração do jogo:

- Se o juiz ditar o resultado 7 e você vê que a carta do outro jogador é 3, qual será a sua carta?

- Se um dos jogadores tem a carta 8 , e o outro, a carta 5 , que número o juiz irá ditar?

- Se cada monte tem baralhos de 1 a 9 , qual o maior número que o juiz poderá ditar? E o menor?

Além dessas intervenções, o professor-formador solicitou aos professores que elaborassem uma pergunta com propostas diferentes das apresentadas. Após as discussões e reflexões geradas nos grupos, as perguntas elaboradas foram apresentadas à turma:

- Que cartas os jogadores podem colocar na testa para o juiz ditar o número 12 ?

- Que cartas os jogadores podem colocar na testa para o juiz ditar um número par?

- Que cartas os jogadores podem colocar na testa para o juiz ditar um número ímpar?

Verificamos que a reflexão sobre as ações vivenciadas no jogo propiciou o desenvolvimento do conhecimento profissional do professor (BALL, 1988; SCHÖN, 1997; SERRAZINA, 2012).

Percebemos, ainda, que alguns professores tiveram mais facilidade na realização das atividades e em expor seus pontos de vista durante as discussões. Outros precisaram de mais tempo 
e da mediação do professor-formador. Dessa forma, ficou evidente o papel do professor-formador como mediador da aprendizagem, instigando o professor orientador a mobilizar e construir seus conhecimentos.

Nos depoimentos registrados na figura 4, apresentamos as concepções dos professores orientadores após vivenciarem jogos matemáticos planejados para os alunos.

Figura 4 - Depoimentos de três professores orientadores de estudos

b) Conhecimentos explorados:.... Alriu caminho atraces dos fogos, abrindo um luque de epcols gara pue ponamon passar para o profuso uma matemática mais significatios e una aprendizagem mais ativa.

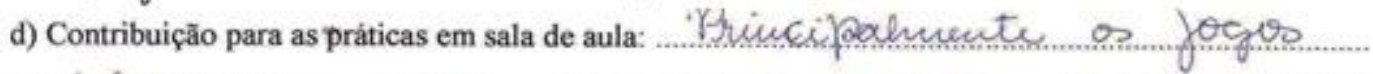
exdalorados perá de gnande valia para prátecos en salo de achas

d) Contribuição para as práticas em sala de aula ...s. matoriaus...utílizados due-

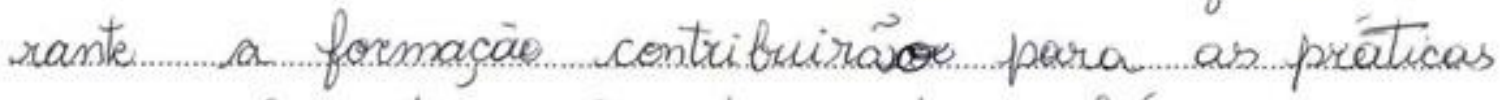
em vala de aula trazendo o híluco paraa retina escolar.

Fonte: Acervo pessoal.

Os depoimentos dos professores orientadores apontam o jogo não apenas como uma prática lúdica, motivadora e prazerosa, mas também como um recurso pedagógico que possibilita um pensar e um refletir. Tais depoimentos são ratificados pelas pesquisas de Silva (2005), Smole et al. (2007), Fialho (2007) e Moretti e Souza (2015), as quais sinalizam o jogo como um recurso motivador para a construção de conhecimentos matemáticos.

\section{Considerações Finais}

Entendemos que é mais promissor para o professor familiarizar-se com um recurso educacional quando ele estabelece relações entre esse recurso e os conhecimentos matemáticos subjacentes. Assim, ao planejarmos atividades com uso de jogos, tivemos essa preocupação e nos fundamentamos na concepção de Shulman (1986) sobre o conhecimento curricular. Esse conhecimento se caracteriza pela habilidade do professor em articular o conteúdo com os materiais que auxiliam na aprendizagem.

As experiências vivenciadas pelos professores promoveram reflexões sobre suas práticas (SCHÖN, 1997). Os professores se colocaram no lugar de seus alunos e se certificaram de que os 
estudantes podem se deparar com as dificuldades e as facilidades com as quais se depararam ao vivenciarem as atividades propostas na formação (BALL, 1991; SERRAZINA, 2012).

Os momentos partilhados ao longo da formação serviram como referência para mostrar ao grupo que a falta do conhecimento do conteúdo matemático constitui um obstáculo para o professor realizar quaisquer atividades com quaisquer recursos. Tais momentos revelam as ideias de Shulman (1986), Ball (1988), Tardif (2002) e Serrazina (2012) sobre o saber da disciplina, indispensável para o pleno exercício da função de ensinar pelo professor.

Foi possível observar que as atividades com jogo, tendo como perspectiva a problematização e a reflexão, possibilitaram o aprimoramento do conhecimento profissional docente, visto que os professores perceberam o jogo como uma possibilidade didático-pedagógica na construção de conceitos matemáticos no Ciclo de Alfabetização (SCHÖN, 1997; SERRAZINA, 2012). Verificamos ainda que a intencionalidade docente na prática de jogos no ensino de Matemática é imprescindível para a construção de conceitos, conforme sugere Starepravo (2009).

Para finalizar, concluímos que a figura do professor-formador, como mediador pedagógico, proporcionou um ambiente que facilitou a aquisição de conhecimento pelos professores orientadores de estudos.

\section{Referências}

BALL, D. L. Knowledge and reasoning in mathematical pedagogy: examining what prospective teachers bring to teacher education. 1988. Tese (Doutorado em Filosofia) - Michigan State University, East Lansing, Michigan, 1988. Disponível em https://deborahloewenbergball.com/pubsintro/\#publications. Acesso em: 26 jan. 2017.

BRASIL. Secretaria de Educação Fundamental. Parâmetros Curriculares Nacionais: Matemática. Brasília, MEC/SEF, 1997. 142 p.

. Secretaria de Educação Básica. Pacto Nacional pela Alfabetização na Idade Certa: Jogos na Alfabetização Matemática. Brasília, MEC/SEB, 2014. 72 p.

FIALHO, N. N. Jogos no Ensino de Química e Biologia. Curitiba: IBPEX, 2007.

MANDARINO, M. C. F. Concepções do ensino de matemática elementar que emergem da prática docente. 2006. 273 f. Tese (Doutorado em Educação) - Pontifícia Universidade Católica, Rio de Janeiro, 2006.

MORETTI, V. D.; SOUZA, N. M. M. de. Educação Matemática nos Anos Inicias do Ensino Fundamental: princípios e práticas pedagógicas. São Paulo: Cortez, 2015.

MOYLES, J. R. Só brincar? O papel do brincar na educação infantil. Tradução: Maria Adriana Veronese. Porto Alegre: Artmed, 2002.

NACARATO, A. M.; MENGALI, B. L. da S.; PASSOS, C. L. B. A Matemática nos Anos Iniciais do Ensino Fundamental: tecendo fios do ensinar e do aprender. Belo Horizonte: Autêntica Editora, 2009. (Coleção Tendências em Educação Matemática).

RIO DE JANEIRO. Edital SMA No 92, de 26 de fevereiro de 2016. 
SCHÖN, D.A. Formar professores como profissionais reflexivos. In: Nóvoa, A. (Org.). Os Professores e a sua Formação. Lisboa, Portugal: Publicações Dom Quixote Instituto de Inovação Educacional, 1997.

SERRAZINA, M. de L. M. Conhecimento matemático para ensinar: papel da planificação e da reflexão na formação de professores. Revista Eletrônica de Educação. São Carlos, SP: UFSCar, v. 6, no. 1, p.266-283, mai. 2012. Disponível em <http://www.reveduc.ufscar.br>. Acesso em: 29 nov. 2016.

SHULMAN, L. S. Those who understand: knowledge growth in teaching. Educational Researcher, v.15, n.2, p.4-14, 1986.

SILVA, M. S. da. Clube de Matemática: jogos educativos. 2.ed. Campinas, SP: Papirus, 2005.

SILVEIRA, R. S; BARONE, D. A. C. Jogos Educativos computadorizados utilizando a abordagem de algoritmos genéticos. Universidade Federal do Rio Grande do Sul. Instituto de Informática. Curso de Pós-Graduação em Ciências da Computação, 1998.

SMOLE, K. S.; DINIZ, M. I.; MILANI, E. Jogos de Matemática de $6^{\circ}$ ao $9^{\circ}$ ano. Porto Alegre: Artmed, 2007.

STAREPRAVO, A. R. Jogando com a matemática: números e operações. Curitiba: Aymará, 2009.

TARDIF, M. Saberes docentes e formação profissional. Petrópolis: Vozes, 2002.

VYGOTSKY, L. S. A formação social da mente: o desenvolvimento dos processos psicológicos superiores. 6 ed. São Paulo: Martins Fontes, 1998. 191 p. 